Published in final edited form as:

Clin Chest Med. 2017 September ; 38(3): 511-520. doi:10.1016/j.ccm.2017.04.011.

\title{
Fungal Infections After Lung Transplantation
}

\author{
Cassie C. Kennedy, MDa and Raymund R. Razonable, MD \\ aDivision of Pulmonary and Critical Care Medicine, William J. von Liebig Center for \\ Transplantation and Clinical Regeneration, Mayo Clinic Robert D. and Patricia E. Kern Center for \\ the Science of Health Care Delivery, Mayo Clinic, 200 First Street Southwest, Rochester, MN \\ 55905, USA \\ bDivision of Infectious Diseases, William J. von Liebig Center for Transplantation and Clinical \\ Regeneration, Mayo Clinic, 200 First Street Southwest, Rochester, MN 55905, USA
}

\section{Keywords}

Solid organ transplantation; Lung transplantation; Fungal infection; Fungal prophylaxis

\section{Introduction}

The first lung transplant was performed in $1963 .{ }^{1}$ Since then, lung transplantation has emerged as a potential lifesaving treatment modality for end-stage chronic obstructive pulmonary disease, interstitial lung disease, pulmonary hypertension, and cystic fibrosis. Since 1988, more than 32,224 lung transplantations have been performed in the United States. ${ }^{2}$ The median survival after adult lung transplantation is approximately $50 \%$ at 5 years. $^{2}$

Survival after lung transplantation is influenced by the occurrence of major complicationsallograft rejection and infection (and their complications). In an effort to improve allograft survival, lung transplant recipients are maintained on an often intense immunosuppressive drug regimen to prevent rejection and maintain allograft function. The downside of this practice, however, is a heightened risk of opportunistic infections, including invasive fungal disease. ${ }^{3}$ Up to $8.6 \%$ of patients develop invasive fungal infections during the first year after lung transplantation, although the incidence rates reported in clinical studies have varied widely depending on multiple factors, such as patient exposures, patient populations, immunosuppressive drug use, center-dependent practices (including the use of antifungal and other antibiotic prophylaxis), duration of study follow-up, and definitions of invasive fungal infection, among other factors. ${ }^{3-5}$

\section{Microbiology and Clinical Manifestations}

The most common pathogens that cause invasive fungal infections after lung transplantation are Aspergillus spp (44\%, most commonly Aspergillus fumigatus), Candida spp (23\%, most commonly $C$ albicans), and other molds, such as Scedosporium spp (20\%). Members of the 
Mucorales group (3\%, including Mucor and Rhizopus), Cryptococcus neoformans (2\%), and the endemic mycoses (1\%, including Histoplasma capsulatum, Cocci-dioides immitis, and Blastomyces dermatitidis) account for only a small proportion of cases. ${ }^{3-6}$ The incidence of P jirovecii was up to $15 \%$ (in the absence of prophylaxis) but this has declined remarkably with the widespread use of prophylaxis. ${ }^{7}$

A majority of invasive fungal infections occur during the first 3 months to 12 months after lung transplantation. Depending on the specific pathogen and associated risk factors, mold infections manifest clinically as ulcerative tracheobronchitis, invasive pulmonary parenchymal disease, disseminated multiorgan disease, and/or fungemia. Candida spp infections, on the other hand, often cause fungemia, mediastinitis, and pleural space infection. Cryptococcus neoformans, H capsulatum, and Coccidioides immitis cause pneumonia, with tendency to disseminate to other organ systems, including the brain. $P$ jirovecii also typically causes pneumonia that manifests with nonproductive cough, hypoxemia, and bilateral interstitial infiltrates. A diagnosis of invasive fungal infections after lung transplantation can be established by demonstration of the fungi in affected tissues.

This can be accomplished with culture of blood, respiratory fluid, and other clinical samples; antigen detection in blood, respiratory fluid, and other clinical samples (eg, galactomannan, $1,3-\beta$-D-glucan, and cryptococcal antigen); nucleic acid testing of clinical samples; and demonstration of the fungal pathogen in affected tissues. ${ }^{6}$

Collectively, invasive fungal infections directly and indirectly contribute to the poor outcome after lung transplantation. ${ }^{3-6}$ They have been associated with a higher risk of bronchiolitis obliterans. ${ }^{8}$ The mortality rate is also generally higher, especially in those with invasive and disseminated disease. Historically, the mortality rate is up to $25 \%$ among those with fungal tracheobronchitis compared with up to $80 \%$ among those with invasive pulmonary aspergillosis. ${ }^{3,4,6,7}$ These rates have declined with the use of more effective anti-fungal drugs. Currently, the overall 3-month mortality rate is up to $22 \%$ of all lung transplant recipients with invasive fungal infection, ${ }^{9}$ whereas 1 -year mortality is up to $44 \% .{ }^{10}$

\section{Risk Factors}

There are several host and environmental factors that increase the risk for invasive fungal infection after lung transplantation. The constant exposure of the transplanted lung to the environment and the abnormal anatomic and physiologic function of the transplanted lung (ie, impaired ciliary function, blunted cough reflex, and denervation injury) predispose to a higher risk of invasive fungal infections. Invasive aspergillosis and other mold infections are more common in older patients, those who have airway ischemia, those who developed cytomegalovirus disease, and those with colonization with Aspergillus spp. ${ }^{1-13}$ Those who received single lung transplants are also at higher risk of invasive fungal infection compared with double lung transplant recipients, because the retained lung (in single lung transplants) can serve as reservoir for potentially pathogenic fungi. Patients with structural lung diseases, such as cystic fibrosis, are often colonized with fungi, most commonly Aspergillus spp, prior to lung transplantation and they have a 4-fold higher risk of invasive aspergillosis. ${ }^{14}$ Colonization of the paranasal sinuses can also serve as reservoir for fungal colonization in patients with cystic fibrosis. The need for bronchial stents also predisposes to higher risk of 
invasive fungal infections, including Candida spp and Aspergillus spp. An

overimmunosuppressed state increases the risk, including those with neutropenia, hypogammaglobulinemia, and T-cell depletion. Lung transplant recipients are especially vulnerable to infection with fungi due to the constant direct exposure of the lung allograft to the outside environment. Environmental exposure is a well-described risk factor for invasive mold infections, especially in areas of farming and construction. ${ }^{15,16}$

\section{Prevention}

Because of the increased risk of invasive fungal infection, and its association with adverse outcomes, ${ }^{3}$ its prevention is a standard of care after lung transplantation. Minimizing environmental exposures, such as avoidance of areas with high concentration of fungal spores (eg, areas of construction) and the use of personal protective equipment (such as masks) during anticipated periods of exposure, are recommendations to reduce the risk. In addition, minimization of indwelling urinary catheters and indwelling central vascular lines help with prevention of Candida spp fungemia and funguria in the perioperative period. Preventing invasive fungal infection can further be accomplished with antifungal drugs for either prophylaxis or preemptive therapy. The drugs that are used for prevention are listed in Table 1.

There is no widely accepted optimal method for prevention, partly due to lack of comparative clinical trials among various strategies. In worldwide surveys conducted among lung transplant centers, only $31 \%$ to $36 \%$ of centers perform preemptive therapy - a strategy of providing antifungal therapy only on detection of fungal infection by surveillance cultures or fungal antigen detection in clinical specimens. ${ }^{17-19}$ Studies have shown that detection of Aspergillus spp on surveillance cultures during the first 3 months after lung transplantation is a good marker for initiation of preemptive therapy. ${ }^{20}$ This preemptive strategy is based on the principle of providing antifungal drugs only to the population at highest risk of invasive fungal disease. This reduces the exposure of most patients tothe adverse effects of antifungal drugs. Its downside, however, is the lack of widely acceptable measure for surveillance that could sensitively capture all fungi (other than Aspergillus spp) that causes invasive fungal disease. Moreover, the isolation of non-aspergillus mold colonization has not been conclusively associated with a higher risk of post-transplant invasive fungal disease. ${ }^{21}$

Accordingly, a majority (59\%-69\%) of transplant centers provide antifungal prophylaxis to lung transplant recipients. ${ }^{17-19}$ There is wide variation, however, in this practice - that is, whether this is given to all lung transplant recipients (universal approach) or only to selected patients (targeted approach) is subject to debate. Likewise, there is no consensus on the choice of antifungal agent, route of administration, and duration of prophylaxis. In a recent survey, the most common anti-fungal drug used is voriconazole, followed by itraconazole and inhaled amphotericin B. ${ }^{18}$ This lack of consensus is partly due to the few prospective data and randomized clinical trials, the variability in lung transplant populations and their risk factors, differences in induction and maintenance immunosuppressive strategies, local availability of various antifungal agents, and other center-dependent characteristics. 


\section{Choice of Antifungal Prophylaxis}

Inhaled amphotericin B is one of the most commonly used drugs for antifungal prophylaxis after lung transplantation, ${ }^{22}$ but its use has declined with the availability of newer triazoles. ${ }^{18} \mathrm{~A}$ broad-spectrum antifungal drug, amphotericin $\mathrm{B}$ is active against the most common fungi causing invasive fungal infection after lung transplantation - Aspergillus spp, Candida spp, and Mucorales group. The protection provided by inhaled administration of amphotericin B, however, is limited only to the aerated lungs. In pharmacokinetic studies performed in lung transplant recipients, inhaled amphotericin B deoxycholate achieves high concentrations in the lower airways of transplanted lungs, but concentrations in native lungs (in the case of single lung transplant) are lower. ${ }^{23}$ It also achieves good concentrations in the airways, thereby providing local delivery to the bronchial anastomosis and proximal areas at risk of infection. In the immediate postoperative period, the blood supply at the anastomosis site is compromised secondary to the surgical practice of forgoing bronchial artery anastomosis to the donor lung. Therefore, this topical approach to antifungal prophylaxis is appealing to many lung transplant centers.

The optimal dosage, formulation (deoxycholate or lipid formulations), and durations of prophylaxis with inhaled amphotericin B are unknown (see Table 1), and, based on surveys, it is highly variable among lung transplant centers. ${ }^{18}$ Daily administration is the most common frequency for the amphotericin B deoxycholate formulation, especially during the early period after lung transplantation when the risk of infection in the bronchial anastomosis is high. Amphotericin B deoxycholate is the most common formulation, but the lipid products are also available for use. ${ }^{24}$ Concentrations of inhaled amphotericin B lipid complex (measured in epithelial lining fluid) and inhaled liposomal amphotericin B (measured in bronchoalveolar lavage aliquots) remain above the minimum inhibitory concentrations of Aspergillus spp for at least 7 days, potentially enabling once-weekly administration. ${ }^{23}$ Inhaled amphotericin B is not systemically absorbed; hence, it is considered safe from the nephrotoxic effects of systemic amphotericin B. Inhaled formulations, however, do not provide protection against fungal infection beyond the airways and lung parenchyma, such as pleural space, mediastinum, blood, and other extrapulmonary tissues. Infections of the pleural space and mediastinum from $C$ albicans, for example, are not prevented by inhaled amphotericin B administration. Such concerns over postoperative mediastinitis, pleuritis, and extrapulmonary infections argue for the need for a systemic antifungal prophylaxis. In a survey of lung transplant centers, up to $20 \%$ of centers provide a combination of inhaled amphotericin B with a systemic azole. ${ }^{18}$

The triazoles are the most commonly used drugs for systemic antifungal prophylaxis after lung transplantation. Voriconazole ${ }^{17,25}$ is the most commonly used triazole, followed by itraconazole ${ }^{3,5,26}$ and posaconazole. ${ }^{18,27,28}$ Oral administration provides systemic antifungal concentrations that are widely distributed invarious tissues, thereby providing antifungal protection to extrapulmonary sites. These antifungal drugs provide broad-spectrum antifungal activity against yeasts (including Candida) and most molds(including Aspergillus), and for posaconazole, against mucormycosis. The use of oral itraconazole, oral suspension of posaconazole, and to a lesser extent voriconazole is complicated by their unpredictable pharmacokinetics. Itraconazole, in particular, has poor to modest absorption 
after oral administration, and acceptable systemic levels may not be achieved with normal recommended dosages. Conversion to liquid formulation, or its coadministration with acidic fluid, may enhance the oral absorption of itraconazole. Conversely, the oral tablet form of posaconazole provides better pharmacokinetics compared with the oral suspension. Therapeutic drug monitoring to document an acceptable systemic itraconazole, posaconazole, and voriconazole levels is generally recommended, ${ }^{29}$ but the optimal trough level that is needed for prophylactic efficacy has not been defined. Drug doses, therefore, vary depending on center-specific practices. The use of systemic triazoles is complicated by numerous drug-drug interactions, because of their potent inhibitory effects on the cytochrome p450 enzyme system. Most commonly, administration of itraconazole and voriconazole results in increased levels of tacrolimus and calcineurin inhibitors. Careful monitoring of potential drug interactions is, therefore, highly emphasized during the use of azoles. Triazoles also have hepatotoxicity, especially when initiated during the immediate postoperative period, and they have the effect of prolonging the QT interval. ${ }^{14}$ Long-term use of voriconazole has also been associated with a heightened predisposition to squamous cell skin cancer ${ }^{30}$ and painful periostitis characterized by the deposition of excess fluoride in the skeletal system. ${ }^{31}$ Fluconazole is not recommended for general antifungal prophylaxis after lung transplantation due to its lack of activity against Aspergillus and other molds. The newest azole drug — isavuconazole — has broad-spectrum activity against Aspergillus spp and Mucor sp, but its clinical utility as antifungal prophylaxis after lung transplantation is not yet supported by solid scientific data.

The echinocandins - caspofungin, micafungin, anidulafungin - are a class of antifungal drugs that has broad-spectrum activity against Candida spp, Aspergillus spp, and other molds. They do not have any activity, however, against Cryptococcus sp, H capsulatum, Coccidioides immitis, and the endemic fungi. The role of echinocandins as antifungal prophylaxis is limited due to lack of oral formulation (hence, prohibitive for long-term use). Their availability only in intravenous formulation makes them useful mainly during empiric and targeted treatment of established invasive fungal infections. They are also potentially useful as anti-fungal prophylaxis during the early period after lung transplantation but often are switched to oral triazole prophylaxis once patients are able to take oral medications. ${ }^{18}$

Lifelong P jirovecii prophylaxis with trimethoprim-sulfamethoxazole is standard practice after lung transplant. Patients with sulfa allergy can often be desensitized after transplant. Those who cannot take trimethoprim-sulfamethoxazole can take alternatives, such as inhaled pentamidine monthly, oral dapsone, or atovaquone therapy.

\section{Duration of Antifungal Prophylaxis}

The duration of antifungal prophylaxis against invasive mold infections is variable among transplant centers. It can be as short as 3 months after lung transplantation and as long as a lifelong strategy in some centers. Most lung transplant centers provide antifungal prevention for 6 months to 12 months. This duration targets the highest risk period for anastomotic fungal infection or ulcerative tracheobronchitis, which occurs within 3 months after lung transplantation, and invasive and disseminated fungal disease, which occur most commonly during the first 6 months to 12 months. ${ }^{3-6}$ Epidemiologic studies, however, have highlighted 
the occurrence of invasive fungal infections beyond this traditional period. Hence, others have attempted to extend the duration of antifungal prophylaxis. Whether this is the optimal approach is not known. This practice increases antifungal drug exposure that also directly increases cost, potential drug resistance, and adverse drug toxicities. There is also emerging data to suggest that the onset of invasive fungal infections may be delayed by use of antifungal prophylaxis. In recent multicenter observational studies, the median time to onset of invasive fungal infections was 184 days ${ }^{4}$ but could be as long as 504 days ${ }^{32}$ after transplantation. Another center reported the median time to onset of 363 days for aspergillosis and 419 days for other mold infections. ${ }^{10}$ This delay in the onset of infections, potentially due to the effect of antifungal prophylaxis during the early period after lung transplantation, has led some centers to further extend the duration of antifungal prophylaxis.

\section{Anastomotic Fungal Infections}

The transplanted lungs are susceptible to anastomotic fungal infections due to Candida spp and Aspergillus spp in the early post-transplant period. Such infections may manifest clinically as change in spirometry, a complaint of noisy breathing, or a feeling of difficulty coughing up secretions. Diagnosis can be suspected with an irregularity of the airway or extraluminal air on chest imaging or the presence of a pseudomembrane on bronchoscopic inspection. Confirmation of diagnosis is made with anastomotic fungal cultures, stains, and biopsies. Positive Aspergillus cultures of respiratory secretions have been strongly associated with the subsequent occurrence of anastomotic complications, hence the need to provide universal or targeted antifungal prophylaxis to these patients. ${ }^{33}$ The incidence of severe fungal pseudomembrane on anastomotic inspection was approximately $15 \%$, with an overall fungal pseudomembrane occurrence in approximately half of the early bronchoscopies after lung transplantation. ${ }^{34}$ The reported incidence of anastomotic fungal infections ranges from $4.9 \%$ to $24.6 \%,{ }^{35,36}$ with "infection" defined as the presence of necrosis or pseudomembrane on bronchoscopic inspection of the anastomosis and biopsy evidence of invasive fungal organism. In 1 series, Aspergillus and Candida comprised a majority of anastomotic infections at $2.1 \%$ and $2.8 \%$ of all recipients, respectively, and $93 \%$ of all anastomotic infections. ${ }^{35}$ These recipients did not differ in survival from the noninfected cohort and there were no incidences of anastomotic dehiscence. In another series, 9.8\% of recipients had Candida spp and 16.4\% had Aspergillus anastomotic infections (including 1 recipient with both organisms). ${ }^{36}$ The airway complication rate after fungal infection in this series was $46.7 \%$, including bronchial stenosis and hemorrhage; the mortality rate was $20 \% .{ }^{36}$ Rare cases of Zygomycetes-associated anastomotic infections have been reported. ${ }^{37}$ See Fig. 1 for an example of an anastomotic dehiscence associated with a Zygomycetes infection in a lung transplant recipient. Empiric treatment of invasive fungal infection should target the most common pathogens (Candida spp and Aspergillus spp), with the use of voriconazole, amphotericin B, or an echinocandin (see Table 1). If Zygomycetes is suspected, amphotericin B, posaconazole, and isavuconazole may be used. The eventual definitive treatment should be tailored based on fungal culture results and antifungal susceptibility pattern. 


\section{Fungal Pneumonias}

Fungal pneumonias in lung transplant recipients are typically suspected based on chest imaging or change in spirometry. Patients may be asymptomatic or have signs and symptoms of pulmonary infection. Imaging may demonstrate an infiltrate, micronodules, or solid nodule(s). A bronchoalveolar lavage can be performed to obtain specimens for fungal stains and cultures. Invasive disease can be demonstrated by transbronchial biopsy or transthoracic needle aspiration. The most common pathogen causing invasive fungal pneumonia is Aspergillus spp. First-line treatment of invasive aspergillus pneumonia is voriconazole, and alternative treatment regimens are amphotericin B formulations (deoxycholate or lipid formulation). Echinocandins are often reserved only as salvage therapy for invasive aspergillosis. Aspergillomas are often treated with surgical resection, often with systemic antifungal therapy. See Fig. 2 for an example of a pulmonary nodule, found on resection to be an aspergilloma in the native lung of a transplant recipient. Pneumonia due to endemic mycoses occur rarely after lung transplantation, probably due to the use of effective antifungal prophylaxis. Likewise, $P$ jiroveci pneumonia has been reduced by trimethoprim-sulfamethoxazole prophylaxis.

\section{Fungal Mediastinitis/Pleural Space Infections}

Fungal mediastinitis and fungal pleural space infections are rare after lung transplantation. Diagnosis can be suspected in cases of pleural effusion (pleural) or with sternal instability, erythema, or purulence (mediastinitis). Imaging may demonstrate fluid collection and/or pleural thickening. Diagnosis must be confirmed by fluid or tissue culture, stains, or pathology. In a large series of 776 thoracic transplant patients, mediastinitis had an incidence of $3.1 \%$ in lung and $5.2 \%$ in heart-lung recipients; Candida spp mediastinitis comprised $14.3 \%$ of the cases and the rest were bacterial. ${ }^{38}$ In contrast, most pleural space infections are caused by fungal infection. ${ }^{39}$ In a series of 455 recipients, the incidence of pleural infections in the first 90 days was $7.5 \%$ with approximately two-thirds (61\%) of these caused by fungus. ${ }^{39}$ Candida spp accounted for $90.1 \%$ of these with Aspergillus causing 9.9\% ${ }^{39}$ The 1-year survival of patients with a pleural space infection in this series was significantly lower than those without infection (67\% vs $87 \%) .{ }^{39}$ Hence, aggressive treatment should be pursued to improve outcome. Surgical debridement and evacuation of infected fluid collections is key and should be complemented by systemic antifungal therapy. Empiric antifungal treatment should target the 2 most common pathogens (Candida spp and Aspergillus spp), either with the use of extended-spectrum triazole (voriconazole) or amphotericin B or an echinocandin. Definitive treatment should be based on fungal culture results and antifungal susceptibility pattern (see Table 1). See Fig. 3 for an example chest CT of a 45-year-old woman who developed a mixed fungal and bacterial pleural space infection after lung transplantation for cystic fibrosis.

\section{Disseminated Fungal Infections}

Disseminated fungal infection in lung transplant recipients is characterized by infection of the blood stream or the involvement of multiple noncontiguous sites. The most common organisms causing invasive fungal infections in solid organ transplant recipients are Candida 
spp and less commonly Aspergillus spp. Much less common are infections due to Cryptococcus neoformans, Scedosporium, Mucormycoses, and Fusarium. ${ }^{4,9}$ Invasive candidiasis is rare in lung transplant recipients (compared with other organ transplant types), and manifests clinically as blood stream infection, often in relation to indwelling vascular catheters. Azoles (including fluconazole), amphotericin B, and echinocandins are effective treatment but should be guided by fungal culture results and susceptibility testing.

Angioinvasive aspergillosis is rarely detected in blood cultures but often manifests with multifocal disease, with abscess formation in extrapulmonary sites, such as central nervous system disease. See Fig. 4 for an example of imaging of central nervous system aspergillosis in a lung transplant recipient.

\section{Summary}

Fungal infections contribute significantly to lung transplant morbidity and mortality. Prevention strategies, including antifungal prophylaxis, are commonly used but controversy remains regarding the optimal drug and duration of prophylaxis. Other common methods of preventing fungal disease (masks, avoidance, and so forth) are encouraged as are best practices to limit patient exposures to lines and hardware. Fungal infections may manifest as invasive anastomosis, lung parenchyma, pleural/mediastinal space, disseminated, or bloodstream infections. The most common pathogens are Aspergillus spp and Candida spp Empiric treatment should, therefore, target these 2 most common pathogens, but definitive treatment should always be guided by fungal cultures and antifungal susceptibility tests.

\section{Acknowledgments}

Dr. C.C. Kennedy is supported by the National Heart, Lung, And Blood Institute (K23HL128859) and Dr. R.R. Razonable is supported by the National Institute of Allergy and Infectious Diseases (0024031-3) of the National Institutes of Health (NIH). The content is solely the responsibility of the authors and does not necessarily represent the official views of the NIH.

\section{References}

1. Hardy JD, Webb WR, Dalton ML Jr, et al. Lung homotransplantation in man. JAMA. 1963; 186:1065-74. [PubMed: 14061414]

2. 2016; Available at: https://www.unos.org/data/. Accessed August 15, 2016.

3. Arthurs SK, Eid AJ, Deziel PJ, et al. The impact of invasive fungal diseases on survival after lung transplantation. Clin Transplant. 2010; 24(3):341-8. [PubMed: 19712081]

4. Pappas PG, Alexander BD, Andes DR, et al. Invasive fungal infections among organ transplant recipients: results of the transplant-associated infection surveillance network (TRANSNET). Clin Infect Dis. 2010; 50(8):1101-11. [PubMed: 20218876]

5. Chong PP, Kennedy CC, Hathcock MA, et al. Epidemiology of invasive fungal infections in lung transplant recipients on long-term azole antifungal prophylaxis. Clin Transplant. 2015; 29(4):311-8. [PubMed: 25604399]

6. Singh N, Husain S. Aspergillosis in solid organ transplantation. Am J Transplant. 2013; 13(Suppl 4): 228-41. [PubMed: 23465016]

7. Martin SI, Fishman JA. Pneumocystis pneumonia in solid organ transplantation. Am J Transplant. 2013; 13(Suppl 4):272-9. [PubMed: 23465020]

8. Weigt SS, Elashoff RM, Huang C, et al. Aspergillus colonization of the lung allograft is a risk factor for bronchiolitis obliterans syndrome. Am J Transplant. 2009; 9(8):1903-11. [PubMed: 19459819] 
9. Doligalski CT, Benedict K, Cleveland AA, et al. Epidemiology of invasive mold infections in lung transplant recipients. Am J Transplant. 2014; 14(6):1328-33. [PubMed: 24726020]

10. Vazquez R, Vazquez-Guillamet MC, Suarez J, et al. Invasive mold infections in lung and heart-lung transplant recipients: Stanford University experience. Transpl Infect Dis. 2015; 17(2):259-66. [PubMed: 25648194]

11. Cahill BC, Hibbs JR, Savik K, et al. Aspergillus airway colonization and invasive disease after lung transplantation. Chest. 1997; 112(5):1160-4. [PubMed: 9367451]

12. Gavalda J, Len O, San Juan R, et al. Risk factors for invasive aspergillosis in solid-organ transplant recipients: a case-control study. Clin Infect Dis. 2005; 41(1):52-9. [PubMed: 15937763]

13. Husni RN, Gordon SM, Longworth DL, et al. Cytomegalovirus infection is a risk factor for invasive aspergillosis in lung transplant recipients. Clin Infect Dis. 1998; 26(3):753-5. [PubMed: 9524855]

14. Luong ML, Chaparro C, Stephenson A, et al. Pre-transplant aspergillus colonization of cystic fibrosis patients and the incidence of post-lung transplant invasive aspergillosis. Transplantation. 2014; 97(3):351-7. [PubMed: 24305637]

15. Raviv Y, Kramer MR, Amital A, et al. Outbreak of aspergillosis infections among lung transplant recipients. Transpl Int. 2007; 20(2):135-40. [PubMed: 17239021]

16. Sole A, Morant P, Salavert M, et al. Aspergillus infections in lung transplant recipients: risk factors and outcome. Clin Microbiol Infect. 2005; 11(5):359-65. [PubMed: 15819861]

17. Husain S, Paterson DL, Studer S, et al. Voriconazole prophylaxis in lung transplant recipients. Am J Transplant. 2006; 6(12):3008-16. [PubMed: 17062003]

18. Neoh CF, Snell GI, Kotsimbos T, et al. Antifungal prophylaxis in lung transplantation-a worldwide survey. Am J Transplant. 2011; 11(2):361-6. [PubMed: 21272239]

19. He SY, Makhzoumi ZH, Singer JP, et al. Practice variation in aspergillus prophylaxis and treatment among lung transplant centers: a national survey. Transpl Infect Dis. 2015; 17(1):14-20. [PubMed: 25620387]

20. Hosseini-Moghaddam SM, Chaparro C, Luong ML, et al. The effectiveness of culture-directed preemptive anti-aspergillus treatment in lung transplant recipients at one year after transplant. Transplantation. 2015; 99(11):2387-93. [PubMed: 25961491]

21. Silveira FP, Kwak EJ, Paterson DL, et al. Post-transplant colonization with non-aspergillus molds and risk of development of invasive fungal disease in lung transplant recipients. J Heart Lung Transplant. 2008; 27(8):850-5. [PubMed: 18656797]

22. Drew RH, Dodds Ashley E, Benjamin DK Jr, et al. Comparative safety of amphotericin B lipid complex and amphotericin B deoxycholate as aerosolized antifungal prophylaxis in lung-transplant recipients. Transplantation. 2004; 77(2):232-7. [PubMed: 14742987]

23. Monforte V, Roman A, Gavalda J, et al. Nebulized amphotericin B concentration and distribution in the respiratory tract of lung-transplanted patients. Transplantation. 2003; 75(9):1571-4. [PubMed: 12792517]

24. Palmer SM, Drew RH, Whitehouse JD, et al. Safety of aerosolized amphotericin B lipid complex in lung transplant recipients. Transplantation. 2001; 72(3):545-8. [PubMed: 11502995]

25. Mitsani D, Nguyen MH, Shields RK, et al. Prospective, observational study of voriconazole therapeutic drug monitoring among lung transplant recipients receiving prophylaxis: factors impacting levels of and associations between serum troughs, efficacy, and toxicity. Antimicrob Agents Chemother. 2012; 56(5):2371-7. [PubMed: 22330924]

26. Kato K, Nagao M, Nakano S, et al. Itraconazole prophylaxis for invasive aspergillus infection in lung transplantation. Transpl Infect Dis. 2014; 16(2):340-3. [PubMed: 24593162]

27. Robinson CL, Chau C, Yerkovich ST, et al. Posaco-nazole in lung transplant recipients: use, tolerability, and efficacy. Transpl Infect Dis. 2016; 18(2):302-8. [PubMed: 26781986]

28. Patterson TF, Thompson GR 3rd, Denning DW, et al. Practice guidelines for the diagnosis and management of aspergillosis: 2016 update by the infectious diseases society of America. Clin Infect Dis. 2016; 63(4):e1-60. [PubMed: 27365388]

29. Thakuria L, Packwood K, Firouzi A, et al. A pharmacokinetic analysis of posaconazole oral suspension in the serum and alveolar compartment of lung transplant recipients. Int $\mathbf{J}$ Antimicrob Agents. 2016; 47(1):69-76. [PubMed: 26607341] 
30. Goyal RK. Voriconazole-associated phototoxic dermatoses and skin cancer. Expert Rev Anti Infect Ther. 2015; 13(12):1537-46. [PubMed: 26488688]

31. Wermers RA, Cooper K, Razonable RR, et al. Fluoride excess and periostitis in transplant patients receiving long-term voriconazole therapy. Clin Infect Dis. 2011; 52(5):604-11. [PubMed: 21239842]

32. Neofytos D, Fishman JA, Horn D, et al. Epidemiology and outcome of invasive fungal infections in solid organ transplant recipients. Transpl Infect Dis. 2010; 12(3):220-9. [PubMed: 20113459]

33. Herrera JM, McNeil KD, Higgins RS, et al. Airway complications after lung transplantation: treatment and long-term outcome. Ann Thorac Surg. 2001; 71(3):989-93. discussion: 993-4. [PubMed: 11269487]

34. Weder W, Inci I, Korom S, et al. Airway complications after lung transplantation: risk factors, prevention and outcome. Eur J Cardiothorac Surg. 2009; 35(2):293-8. discussion: 298. [PubMed: 19004637]

35. Hadjiliadis D, Howell DN, Davis RD, et al. Anastomotic infections in lung transplant recipients. Ann Transplant. 2000; 5(3):13-9. [PubMed: 11147024]

36. Nunley DR, Gal AA, Vega JD, et al. Saprophytic fungal infections and complications involving the bronchial anastomosis following human lung transplantation. Chest. 2002; 122(4):1185-91. [PubMed: 12377840]

37. McGuire FR, Grinnan DC, Robbins M. Mucormycosis of the bronchial anastomosis: a case of successful medical treatment and historic review. J Heart Lung Transplant. 2007; 26(8):857-61. [PubMed: 17692792]

38. Abid Q, Nkere UU, Hasan A, et al. Mediastinitis in heart and lung transplantation: 15 years experience. Ann Thorac Surg. 2003; 75(5):1565-71. [PubMed: 12735580]

39. Wahidi MM, Willner DA, Snyder LD, et al. Diagnosis and outcome of early pleural space infection following lung transplantation. Chest. 2009; 135(2):484-91. [PubMed: 19017896] 


\section{Keypoints}

- Incidence of invasive fungal infections after lung transplantation is variable, with a mean incidence of $8.6 \%$.

- $\quad$ Prevention is a key management strategy for lung transplant recipients with most lung transplant centers providing antifungal prophylaxis for at least 3 months to 6 months postoperatively.

- Although prophylaxis drug regimens vary, common themes include the use of an azole therapy with or without inhaled amphotericin B product (to prevent invasive molds and yeast infections) and trimethoprim-sulfamethoxazole (to prevent Pneumocystis jirovecii).

- Manifestations of invasive fungal disease include pneumonia, pleural/ mediastinal space infections, anastomotic infections, and disseminated disease. 

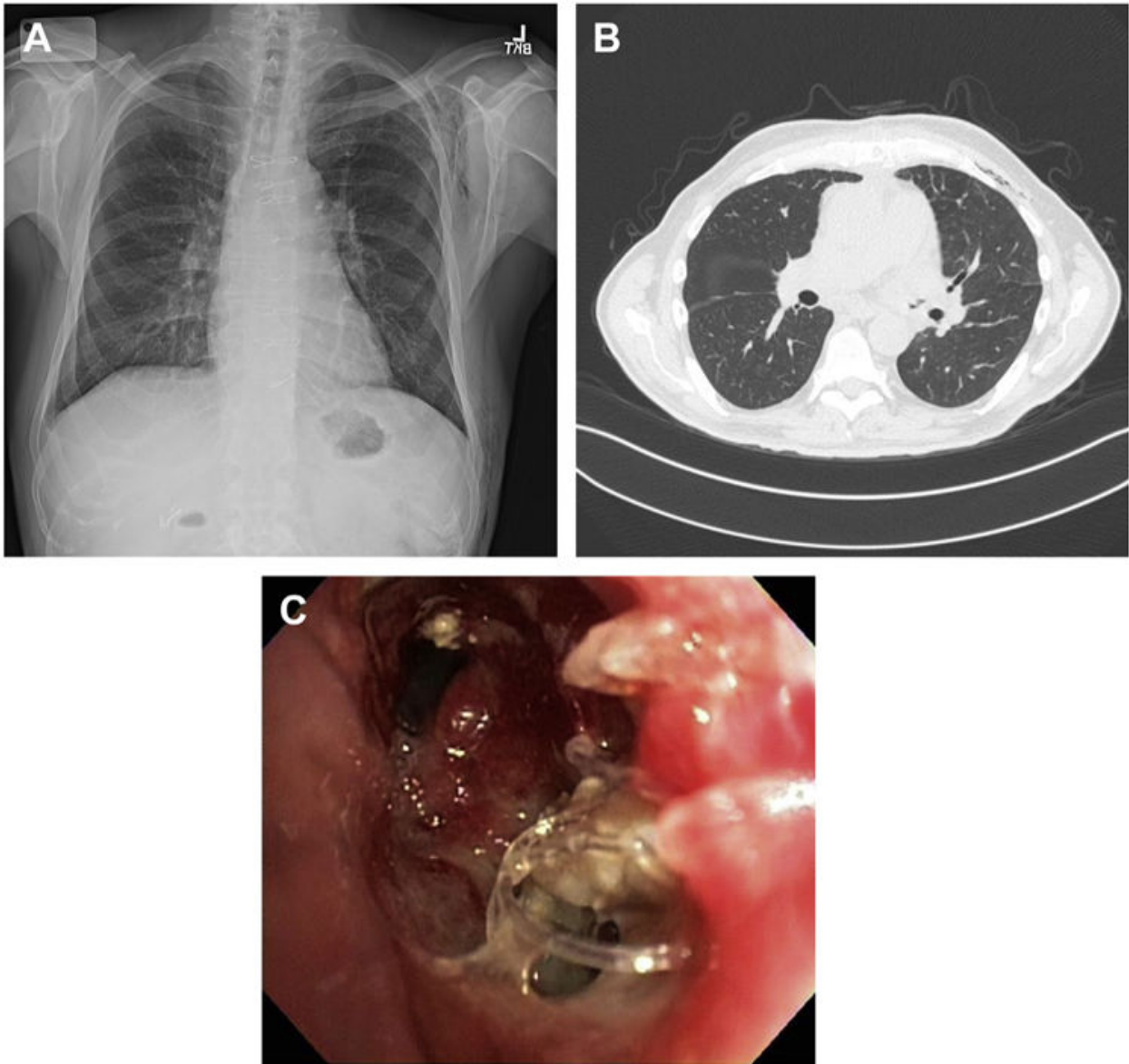

Fig. 1.

Fungal anastomotic infection. Example of anastomotic dehiscence after single left lung transplant with associated positive bronchial culture for Zygomycetes. This 66-year-old male transplant recipient presented with noisy breathing and fall in spirometry 6 weeks after transplant. (A) Shows the chest radiograph with left bronchial irregularity and subcutaneous emphysema. (B) Shows the CT chest with air outside the bronchial tree and subcutaneous emphysema. (C) Demonstrates the findings at bronchoscopy of left bronchial anastomotic dehiscence with visible sutures. Patient responded to liposomal amphotericin B therapy and was converted to lifelong posaconazole therapy. The airway stenosed as it healed and the patient eventually required endoscopic balloon and silicone stent placement in the left airway. 


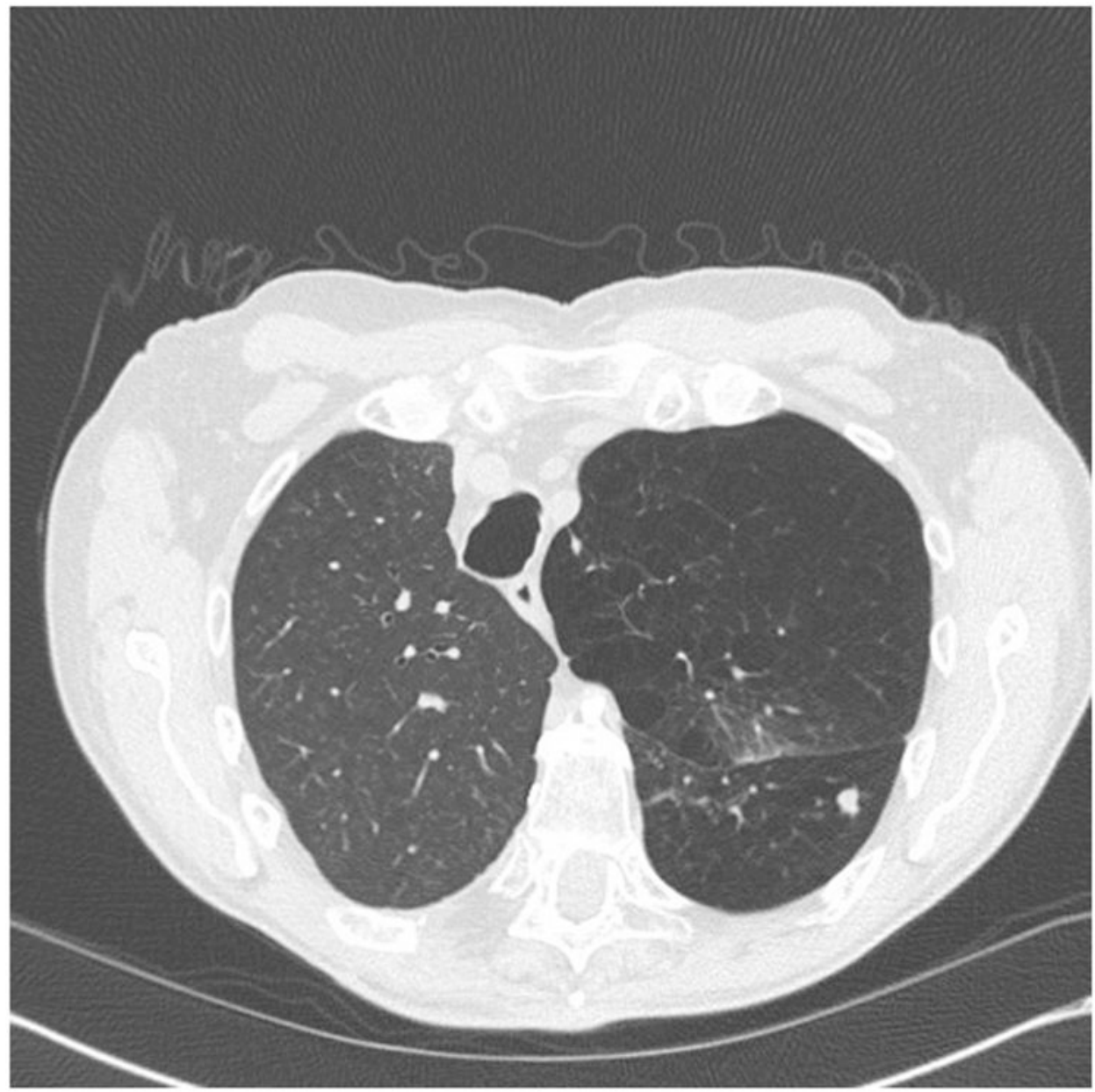

Fig. 2.

Aspergilloma. Asymptomatic, 67-year-old man presents 6 months after right single lung transplant for $\mathrm{a}_{1}$-antitrypsin deficiency with a new native lung nodule. This was found to be an aspergilloma on resection. 


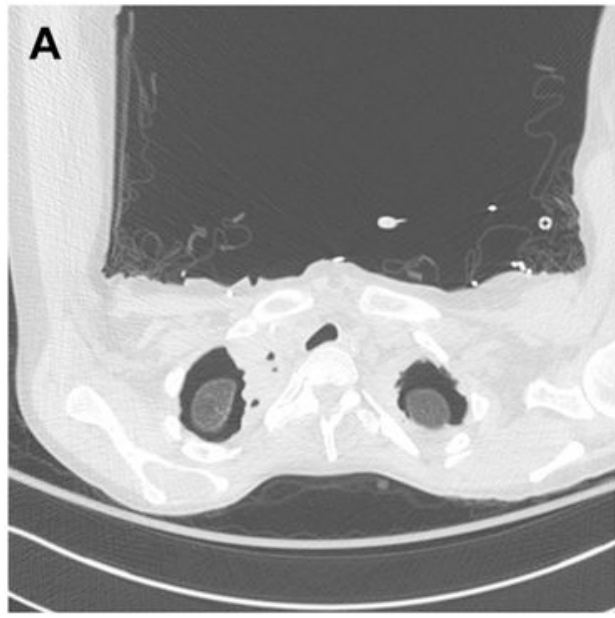

\section{B}

Fig. 3.

Complicated postoperative bacterial and fungal pleural space infection. A 45-year-old woman with bilateral lung transplant for cystic fibrosis. At the time of transplant, the native lung apices were fused to the chest wall and diseased such that complete excision was not possible. The patient developed complicated, multiorganism pleural space infection with Mycoplasma salivarium, Pseudomonas aeruginosa, $C$ albicans, and Aspergillus fumigatus spp. (A) Chest CT 9 days postoperative. (B) Chest CT 15 days postoperative. 

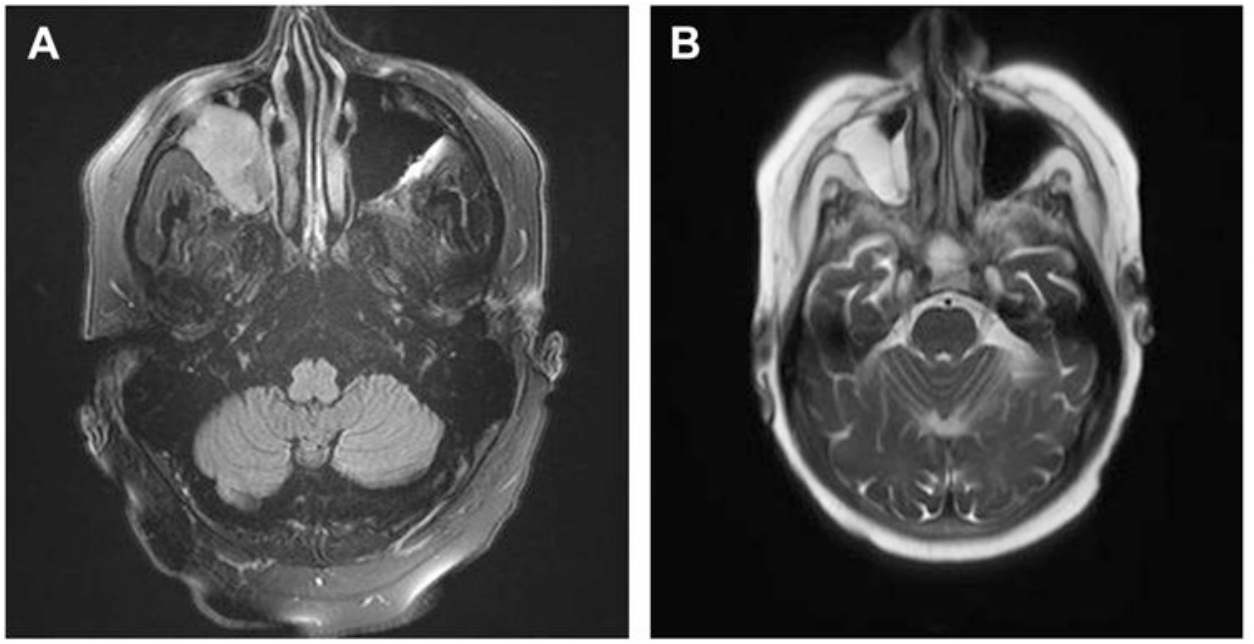

Fig. 4.

Central nervous system aspergillosis. A 61-year old man 11 months post-lung transplant presented with right sided headache, double vision, and conjunctivitis. Head imaging demonstrated a right orbital mass. Biopsy demonstrated necrosis, inflammation, and numerous invading narrow-septate hyphae. Cultures grew Aspergillus fumigatus. Patient was treated with liposomal amphotericin $\mathrm{B}$, followed by caspofungin and voriconazole, then ultimately lifelong posaconazole therapy. 
Table 1

\section{Antifungal drugs for the prevention and treatment of fungal infections after lung} transplantation

\begin{tabular}{|c|c|c|c|}
\hline Class & Drugs & Clinical Applications & Comments \\
\hline \multirow[t]{3}{*}{ Amphotericin B products } & AmB deoxycholate & $\begin{array}{l}\text { Prevention: inhaled formulation; variable } \\
\text { dose and duration }(\mathrm{eg}, 25 \mathrm{mg} / \mathrm{d}) \\
\text { Treatment: } 0.25-1.5 \mathrm{mg} / \mathrm{kg} \text { IV daily (dose } \\
\text { varies depending on pathogen) }\end{array}$ & $\begin{array}{l}\text { Inhaled formulation does not } \\
\text { protect against extrapulmonary } \\
\text { fungal infections } \\
\text { Systemic formulation is } \\
\text { associated with infusion-related } \\
\text { and renal toxicity. }\end{array}$ \\
\hline & AmB lipid complex & $\begin{array}{l}\text { Prevention: inhaled formulation; variable } \\
\text { dose and duration (eg, } 50 \mathrm{mg} \text { every } 2 \mathrm{~d} \text { or } \\
\text { weekly) } \\
\text { Treatment: } 5 \mathrm{mg} / \mathrm{kg} \text { IV daily }\end{array}$ & $\begin{array}{l}\text { Inhaled formulation does not } \\
\text { protect against extrapulmonary } \\
\text { fungal infections. } \\
\text { Systemic formulation is } \\
\text { associated with infusion-related } \\
\text { and renal toxicity but at lower } \\
\text { risk compared with AmB } \\
\text { deoxycholate. }\end{array}$ \\
\hline & AmB liposome & $\begin{array}{l}\text { Prevention: inhaled formulation; variable } \\
\text { dose and duration (eg, } 25 \mathrm{mg} \text { every } 2 \mathrm{~d} \text { or } \\
\text { weekly) } \\
\text { Treatment: } 3-5 \mathrm{mg} / \mathrm{kg} \text { IV daily (up to } 10- \\
\text { mg/kg daily has been used) }\end{array}$ & $\begin{array}{l}\text { Inhaled formulation does not } \\
\text { protect against extrapulmonary } \\
\text { fungal infections. } \\
\text { Systemic formulation is } \\
\text { associated with infusion-related } \\
\text { and renal toxicity but at lower } \\
\text { risk compared with AmB } \\
\text { deoxycholate. }\end{array}$ \\
\hline \multirow[t]{5}{*}{ Azoles } & Fluconazole & $\begin{array}{l}\text { Prevention: not recommended } \\
\text { Treatment: } 200-800 \mathrm{mg} \text { IV or po daily }\end{array}$ & $\begin{array}{l}\text { Not recommended for } \\
\text { prophylaxis due to lack of } \\
\text { activity against Aspergillus spp } \\
\text { and other molds. } \\
\text { Used for treatment of candida, } \\
\text { endemic fungi, and } \\
\text { crytococcocus. } \\
\text { Drug interaction with CNI }\end{array}$ \\
\hline & Isavuconazole & $\begin{array}{l}\text { Prevention: no data } \\
\text { Treatment: } 200 \mathrm{mg} \text { po/IV every } 8 \mathrm{~h} \text { for } 6 \\
\text { doses, then once daily }\end{array}$ & $\begin{array}{l}\text { Limited data for use as } \\
\text { prophylaxis } \\
\text { Treatment of invasive } \\
\text { aspergillosis and mucormycosis } \\
\text { Drug interaction with CNI }\end{array}$ \\
\hline & Itraconazole & $\begin{array}{l}\text { Prevention and treatment: } 200 \mathrm{mg} \text { po tid for } \\
3 \mathrm{~d} \text {, then bid } \\
\text { Treatment: } 200 \mathrm{mg} \text { po tid for } 3 \mathrm{~d} \text {, then bid }\end{array}$ & $\begin{array}{l}\text { Therapeutic drug monitoring is } \\
\text { recommended but no consensus } \\
\text { on effective drug levels. } \\
\text { Drug interaction with CNI }\end{array}$ \\
\hline & Posaconazole & $\begin{array}{l}\text { Prevention and treatment: } \\
\text { Oral suspension }-200 \mathrm{mg} \text { po tid } \\
\text { Tablet }-300 \mathrm{mg} \text { po bid } \times 2 \text { doses, then } \\
\text { once daily } \\
\text { IV }-300 \mathrm{mg} \text { bid } \times 2 \text { doses, then once } \\
\text { daily }\end{array}$ & $\begin{array}{l}\text { Active against candida, } \\
\text { aspergillosis } \\
\text { Can be used for zygomycosis } \\
\text { Drug interaction with CNI }\end{array}$ \\
\hline & Voriconazole & $\begin{array}{l}\text { Prevention and treatment: } \\
\text { Oral }-200 \mathrm{mg} \text { po bid } \\
\mathrm{IV}-6 \mathrm{mg} / \mathrm{kg} \text { every } 12 \mathrm{~h} \text { for } 24 \mathrm{~h} \text {, then } 4 \\
\mathrm{mg} / \mathrm{kg}\end{array}$ & $\begin{array}{l}\text { Most common azole used for } \\
\text { prophylaxis; therapeutic drug } \\
\text { monitoring to guide dose } \\
\text { Drug interaction with CNI }\end{array}$ \\
\hline \multirow[t]{3}{*}{ Echinocandins } & Anidulafungin & $\begin{array}{l}\text { Treatment: } 200 \mathrm{mg} \text { IV loading dose, then } \\
100 \mathrm{mg} \text { daily }\end{array}$ & $\begin{array}{l}\text { Not recommended for long-term } \\
\text { prophylaxis }\end{array}$ \\
\hline & Caspofungin & $\begin{array}{l}\text { Treatment: } 70 \text { mg IV loading dose, then } 50 \\
\text { mg IV once daily }\end{array}$ & $\begin{array}{l}\text { Not recommended for long-term } \\
\text { prophylaxis }\end{array}$ \\
\hline & Micafungin & Treatment: $100 \mathrm{mg}$ IV once daily & $\begin{array}{l}\text { Not recommended for long-term } \\
\text { prophylaxis }\end{array}$ \\
\hline
\end{tabular}




\begin{tabular}{|c|c|c|c|}
\hline Class & Drugs & Clinical Applications & Comments \\
\hline \multirow[t]{2}{*}{ Others } & Flucytosine & $\begin{array}{l}\text { Treatment: } 50-150 \mathrm{mg} / \mathrm{kg} / \mathrm{d} \text { po in divided } \\
\text { doses }\end{array}$ & $\begin{array}{l}\text { Used in combination with } \\
\text { amphotercin B for treatment of } \\
\text { cryptococcosis } \\
\text { Not recommended for } \\
\text { prophylaxis } \\
\text { Should not be used alone }\end{array}$ \\
\hline & Trimethoprim-sulfamethoxazole & $\begin{array}{l}\text { Prevention: variable dose (single-strength } \\
\text { to double-strength tablet once daily to } 3 \\
\text { times weekly) } \\
\text { Treatment: } 75-100 \mathrm{mg} / \mathrm{kg} / \mathrm{d} \text { of } \\
\text { sulfamethoxazole or } 15-20 \mathrm{mg} / \mathrm{kg} / \mathrm{d} \text { of } \\
\text { trimethoprim in divided doses every } 6 \mathrm{~h} \text { for } \\
14-21 \mathrm{~d}\end{array}$ & $\begin{array}{l}\text { Prevention and treatment of } P \\
\text { jiroveci }\end{array}$ \\
\hline
\end{tabular}

Abbreviations: AmB, amphotericin B; CNI, calcineurin inhibitor; IV, intravenous. 